\title{
Pengembangan Lembar Kerja Praktikum Berbasis Diagram Vee Guna Memfasilitasi Kegiatan Laboratorium Secara Bermakna
}

\author{
Anna Fitri Hindriana ${ }^{1)}$ \\ ${ }^{1}$ Program Studi Pendidikan Biologi, FKIP Universitas Kuningan \\ Email: anna@uniku.ac.id
}
APA Citation: Hindriana, A., F. (2020). Pengembangan Lembar Kerja Praktikum Berbasis Diagram Vee Guna Memfasilitasi Kegiatan Laboratorium Secara Bermakna. Quagga: Jurnal Pendidikan dan Biologi, 12(1), 62-68. doi: 10.25134/quagga.v12i1.2331.

Received: $17-12-2019$

Accepted: 08-01-2020

Published: 25-01-2020

\begin{abstract}
Abstrak: Lembar Kerja Praktikum untuk melaksanakan praktikum saat ini umumnya masih menuntun siswa melaksanakan verifikasi atau confirmatory saja, sehingga kegiatan praktikum menjadi tidak bermakna, karena hasil praktikum hanya berupa klarifikasi teori atau konsep saja. LKP yang digunakan untuk melaksanakan praktikum harus mendukung pemerolehan hakikat sains sehingga kegiatan praktikum menjadi bermakna. Tujuan penelitian ini untuk mengembangkan LKP yang dapat memfasilitasi siswa membangun pengetahuan, nilai dan keterampilan dari kegiatan praktikum. Berdasarkan kajian tersebut dikembangkanlah LKP berbasis diagram vee yang memiliki karakteristik pengembangan valuasi biologi, internalisasi pengetahuan, persepsi proses sains, serta transformasi dan analisis. Data dianalisis secara deskriptif. Validator terdiri dari 3 orang ahli dan pada tahap uji coba melibatkan 12 orang guru yang akan menggunakan LKP hasil pengembangan. Hasil uji validasi LKP yang dikembangkan memperoleh nilai 92,5 dengan kategori layak, hasil penilaian guru untuk karakteristik LKP memperoleh nilai 3,73/4 dan kebermaknaan memperoleh nilai 3,44/4.
\end{abstract}

Kata Kunci : Lembar kerja praktikum; Diagram vee; Bermakna.

\begin{abstract}
Experiment worksheet for laboratory activity are generally only guiding the students to do verification and confirmatory, thus the experiments become less meaningful because the result of experiment only come as clarification of theory or concept. The experiment worksheets used in experiment should have supported the attainment of the science value and put the meaning to the experiment. Based on the problem, this study aims to develop experiment worksheet that can facilitate students to construct knowledge, value, and skill from laboratory experiment. In regards with the objective, Vee diagram based experiment worksheet was developed, which has characteristics of Biology valuation development, knowledge internalization, science process perception, and transformation and analyzation. The data in this study was analyzed descriptively. The validator were 12 teachers who used the experiment worksheet developed in this study. The validation test of the experiment worksheet showed value of 92.5 which is described as decent, meanwhile the judgment from teachers showed value of 3.73/4 for character of experiment and 3.44/4 for meaningfulness.
\end{abstract}

Keyword : Experiment worksheet, Vee diagram, Meaningfulness.

\section{PENDAHULUAN}

Secara teoritis pelaksaan praktikum jelas dapat mengembangkan potensi siswa menguasai kemampuan kognitif, psikomotor dan sikap, namun pada kenyataannya pelaksanaan praktikum di sekolah pada umumnya tidak memberikan makna bagi peserta didik, hal tersebut dikarenakan pelaksanaan praktikum selama ini cenderung hanya bersifat klarifikasi terhadap konsepkonsep yang dipelajari oleh siswa. Kegiatan laboratorium yang dilakukan oleh siswa menjadi tidak bermakna dikarenakan LKP yang ada hanya menuntun siswa melaksanakan verifikasi atau confirmatory saja. Hal tersebut tentu bertentangan dengan prinsip IPA bahwa 
seseorang yang belajar IPA tidak boleh hanya menerima pengetahuan saja akan tetapi juga harus tahu bagaimana cara mendapatkan pengetahuan, hal ini sesuai dengan pernyataan Safdar et al (2013) bahwa tujuan kegiatan laboratorium dalam mempelajari sains di sekolah adalah : (1) memberikan pengalaman praktek bagaimana saintis menggunakan metode saintifik untuk melakukan observasi terhadap alam, dengan mengajukan hipotesis dan melakukan eksperimen untuk memperoleh bukti-bukti dalam mendukung atau menyangkal hipotesis. (2). Mahir dalam melaksanakan praktikum, menggunakan alat-alat laboratorium, mengolah data dan mampu untuk menerapkan teori sains. Berdasarkan apa yang dinyatakan Safdar jelaskah bahwa LKP yang ada di sekolah belum dapat memfasilitasi siswa-siswa untuk melaksnakan praktikum secara bermakna. Keadaan demikian tentu sangat mengkhawatirkan, karena kegiatan praktikum tidak sesuai dengan tujuan semula, dan hakikat dari pembelajaran sains tidak akan terpenuhi. Peserta didik tidak dapat memaknai kegiatan praktikum, karena mereka tidak mendapatkan manfaat dari kegiatan tersebut. Guru merasa kesulitan mencari makna dalam merancang praktikum, terutamama dalam mengembangkan konsep esensial, keterampilan, dan menanamkan sikap dari pelaksanaan praktikum. Beban guru dalam merancang eksperimen yang sesuai dengan tuntutan kurikulum cukup tinggi. Sebagian besar guru tidak mampu menghubungkan konsep dengan metode pada saat merancang eksperimen. Untuk membuat LKP agar kegiatan praktikum menjadi bermakna, digunakan diagram vee untuk membantu guru dalam melaksanakan praktikum secara bermakna.

Diagram vee yang dikembangkan oleh Novak \& Gowin (2006) dapat membantu guru agar peserta didik menghayati arti pekerjaan laboratorium, membantu berpikir reflektif melalui pertanyaan-pertanyaan kunci, membantu melihat hubungan apa yang peserta didik ketahui dengan pengetahuan baru yang akan mereka hasilkan melalui praktikum, dan membantu peserta didik memahami proses bagaimana manusia menghasilkan pengetahuan. Dengan demikian diagram Vee mempermasalahkan pengetahuan dan hakikat belajar secara komplementer. Penggunaan diagram vee untuk merancang praktikum dapat memfasilitasi guru memproses informasi dari buku teks untuk membuat makna baru dengan mengkaitkan fakta yang didapat dari hasil praktikum dengan konsep yang ada di dalam buku teks. Dengan demikian diharapkan penggunaan diagram vee dapat mengembangkan potensi siswa pada aspek kognitif, afektif dan psikomotor, selain itu pelaksanaan praktikum di sekolah akan lebih mengembangkan hakikat sains, dimana nilainilai yang terdapat di dalam sains dapat berguna untuk membentuk watak peserta didik.

Diagram Vee membantu menemukan makna bahwa pengetahuan berasal dari kejadian/objek permasalahan yang diamati (Novak dan Gowin, 2006). Selain itu dalam membuat diagram vee pada sisi kanan dan sisi kiri harus saling berhubungan. Pada pembuatan catatan harus sesuai dengan konsep agar diproleh tranformasi yang mengarah pada kalim pengetahuan yang valid. Begitupun dengan membuat transformasi harus berhubungan dengan prinsip dan klaim pengetahuan harus berhubungan dengan teori. Jika semuanya saling berhubungan maka akan diperoleh suatu pengetahuan yang bermakna berasal dari kejadian / obek yang diamati. (Gencer, 2014). Komponen-komponen diagram vee membantu siswa untuk membangun dan memahami pengetahuan sehingga siswa menyadari apa yang akan dilakukan, apa yang sedang dipelajari, serta pengetahuan apa yang diperoleh setelah melaksanakan kegiatan praktikum (Alvarez \& Risko, 2007).

Komponen-komponen tersebut menurut Novak dan Gowin (2006) dikelompokkan menjadi dua bagian, sisi konseptual (conseptual side) dan sisi metodologikal ( methodological side). Sisi konseptual meliputi konsep (concept), prinsip (principles), teori (theory) dan filosofi (philosophie). Sedangkan sisi metodologikal meliputi pencatatan (record), transformasi (transformation), interpretasi (interpretation) dan perolehan pengetahuan (knowledge claim). 


\section{METODOLOGI PENELITIAN}

Penelitian ini merupakan penelitian kualitatif menggunakan pendekan DBR (Design Based Research) atau desain berbasis penelitian yang bertujuan untuk mengembangkan Lembar Kerja Praktikum sehingga kegiatan praktikum menjadi bermakna. Pendekatan DBR meliputi empat tahap umum yaitu sebagai berikut (Amiel dan Reeves, 2008): 1. Identifikasi dan analisis masalah 2. Perancangan solusi 3. Siklus berulang dalam pengujian dan penyempurnaan rancangan 4. Refleksi untuk menghasilkan prinsip-prinsip desain dan implementasi. Penelitian pengembangan LKP berbasis diagram vee divalidasi oleh 3 orang ahli, yaitu ahli konten, ahli bahasa dan ahli pembelajaran. Uji coba LKP berbasis diagram Vee melibatkan 12 guru biologi SMA di Wilayah III Cirebon.

Pengembangan LKP dilakukan pada sisi konseptual dan sisi metodolikal diagram Vee (Novak dan Gowin, 2006). Sisi konseptual dikembangkan; (1) dasar nilai saat mempelajari sains sehingga akan berhubungan dengan perolehan nilai pada sisi metodologikal, (2) menyajikan pengetahuan secara komprehensip sehingga ada keterhubungan antara teori, prinsip dan konsep untuk memandu pencatatan dan transformasi pada sisi metodologikal, (3) keterampilan proses sains pada saat pelaksanakan praktikum (even/object). Sisi metodologikal dikembangkan; (1) transformasi data untuk melihat pola dari hasil praktikum dengan cara merubah representasi dari tabel menjadi grafik dengan merujuk pada komponen prinsip pada sisi konseptual, (2) analisis menekankan pada interpretasi data hasil pengamatan dengan merujuk pada komponen teori pada sisi konseptual.

Berdasarkan hasil pengembangan diatas, Lembar Kerja Praktikum berbasis diagram vee yang dikembangkan memiliki karakteristik sebagai berikut yaitu mengembangkan nilainilai yang terkandung dalam sains (Valuasi Biologi). Pengembangan nilai-nilai biologi dalam LKP tercantum dalam (1) landasan teori, dimana siswa diberikan informasi tentang dasar nilai dalam mempelajari suatu materi biologi, sehingga siswa memiliki persepsi positif terhadap apa yang dipelajarinya dan siswa mengetahui manfaat mempelajari materi biologi. (2) evaluasi, diarahkan untuk menghasilkan klaim nilai, dimana pertanyaanpetanyaan yang diberikan pada siswa menuntut jawaban bagaimana mengaplikasikan hasil eksperimen dengan permasalahan dalam kehidupan sehari-hari.

Mengembangkan pengetahuan secara komprehensip (Internalisai Pengetahuan). Internalisasi pengetahuan dalam LKP tercantum pada landasan teori yang bertujuan untuk memberikan informsi kepada siswa tentang bagaimana fenomena alam/objek tersebut terjadi, bagaimana menyelidiki dan bagaimana mengamati kejadian fenomena alam/objek tersebut. Dalam landasan teori diinformasikan tentang : (a) Teori yaitu hubungan konsep dan prinsip dalam menggambarkan suatu peristiwa/ kejadian serta menjawab mengapa objek dan peristiwa itu terjadi. (b) Konsep dasar adalah ide utama yang berkaitan dengan aktivitas belajar melalui penyelidikan. (c) Prinsip adalah hubunganhubungan antar konsep satu dengan konsep lain yang diperoleh dari pengetahuan sebelumnya serta menjawab menggunakan metode apa objek dan peristiwa diamati.

Mengembangkan Keterampilan Proses Sains ( Persepsi Proses Sains). Persepsi Proses Sains merupakan usaha siswa dalam memahami informasi yang diperolehnya melalui langkahlangkah ilmiah dan mengelola informasi hasil praktikum agar memiliki makna. Dalam LKP yang dikembangkan menuntut siswa untuk mengembangkan keterampilan proses sains dalam mengumpulkan informasi melalui pengujian hipotesis, observasi, klasifikasi, interpretasi, merencanakan percobaan dan menggunakan alat bahan.

Mengembangkan kemampuan Transformasi dan Analisis Data (Transformasi dan Analisis). Transformasi merupakan kegiatan siswa dalam melakukan pencatatan objek atau peristiwa selama kegiatan praktikum sesuai dengan tujuan praktikum yang diharapkan. Pencatatan ini dapat ditransformasikan ke dalam bentuk tabel, grafik, charta maupun secara statistik. Analisis merupakam kegiatan 
mahasiwa dalam mangaplikasikan pengetahuan yang telah diperolehnya baik dari aspek Internalisasi Pengetahuan maupun Persepsi Proses Sains.

\section{HASIL DAN PEMBAHASAN}

Hasil Validasi LKP Berbasis Diagram Vee

Validasi pada LKP berbasis diagram vee divalidasi olah tiga orang ahli, yaitu ahli bahasa. ahli konten dan ahli pembelajaran. Berdasarkan penilaian didapatkan hasil sebagai berikut :

Tabel 1. Hasil Uji Validasi LK Pengembangan

\begin{tabular}{lcc}
\hline $\begin{array}{c}\text { Aspek } \\
\text { Penilaian }\end{array}$ & Nilai & Ketegori \\
\hline Kelayakan isi & 90,2 & Layak \\
Kebahasaan & 89,3 & Layak \\
Penyajian & 90,5 & Layak \\
$\quad$ materi & 100 & Layak \\
Kegrafikan & Layak \\
$\begin{array}{c}\text { Rata-rata } \\
\text { Presentase }\end{array}$ & 92,5 & L \\
\hline
\end{tabular}

Berdasar hasil validasi LKP secara kualitatif dapat dinyatakan bahwa LKP berbasis diagram vee yang dikembangkan dapat memperbaiki LKP yang biasa digunakan di sekolah, hal ini dikarenakan LKP yang dikembangkan memfasilitasi siswa untuk berinkuiri dan lebih bersifat kontekstual hal ini terlihat dari hasil penilaian pada aspek penyajian materi dan aspek pembelajaran. Selain itu juga memfasilitasi siswa untuk fokus terhadap apa yang harus mereka amati, hal ini dikarenakan LKP dapat mengarahkan siswa untuk mengamati berdasarkan tujuan praktikumnya, hal ini sesuai dengan hasil penilaian pada aspek kelayakan isi . Serta memudahkan pelaksanaan praktikum, karena dalam memberikan informasi tentang bagaimana fenomena alam/objek tersebut terjadi, bagaimana menyelidiki dan bagaimana mengamati kejadian fenomena alam/objek tersebut.

LKP berbasis diagram vee juga memfasilitasi siswa dalam menerapkan hasil praktikum dalam kehidupan sehari-hari. Hal ini dikarenakan LKP mengarahkan siswa untuk mendapat perolehan nilai (valuasi) yang dapat diterapkan dalam kehidupan sehari-hari. Dan dasar teori dalam LKP yang dikembangkan mengarahkan siswa untuk melakukan pengamatan, hal ini dikarenakan dalam dasar teori mengandung konsep dasar dan prinsip dimana konsep dasar adalah ide yang mengarahkan kepada aktivitas penyelidikan (apa yang harus diselidiki siswa) dan prinsip mengarahkan siswa untuk bagaimana objek dan peristiwa diamati.

Berdasarkan hasil pengembangan LKP, beberapa aspek yang ada dalam LKP tersebut adalah (1) Valuasi biologi dalam LKP yang dikembangkan bertujuan untuk mengembangkan kompetensi isi pada aspek religius dan sikap, serta mengembangkan nilainilai yang terkandung yang terkandung dalam biologi. Hal ini dikarenakan valuasi biologi yang dikembangkan dalam LKP berbasis diagram vee memfasilitasi munculnya nilainilai biologi yang berhubungan dengan tanggung jawab moral, nilai-nilai sosial, manfaat biologi untuk kehidupan manusia dan membangun scientific mind. Siswa akan menyadari adanya sang pencipta yang telah menciptakan keteraturan di muka bumi ini, dan ciptaan-Nya akan menghasilkan sinergitas antara alam dan makhluk hidup yang ada di dalamnya. Selain itu valuasi pun akan memunculkan sikap positif terutama terhadap manfaat mempelajari biologi. Sikap inilah yang akan berkembang menjadi scientific mind yang tertanam dalam diri siswa, Hasil penelitian tersebut sesuai dengan pendapat beberapa peneliti lain bahwa Scientific mind berkorelasi positif dengan science process skills, dan science process skills berpengaruh terhadap pencapaian hasil belajar, kemampuan berpikir dan sikap positif terhadap sains (Farsakoğlu et al., 2012; Agoro \& Akinsola, 2013). (2) Internalisasi pengetahuan dalam LKP yang dikembangkan ini bertujuan agar siswa setelah melaksanakan praktikum mendapatkan teori yang komprehensif. Dengan dicantumkannya dasar teori, konsep dasar dan prinsip, memberikan informasi secara komprehensif sehingga siswa dibantu dalam hal apa yang diamati dan metode apa yang digunakan untuk mengamati objek/peristiwa. Dengan adanya informasi yang komprehensif pada LKP yang 
dikembangkan dapat dinyatakan bahwa LKP tersebut merupakan alat bantu (Schaffolding) untuk melaksanakan praktikum. Hal ini sesuai dengan pendapat Ormrod (2008), bahwa scaffolding membantu perkembangan kognitif siswa, sehingga siswa mampu menyelesaikan berbagai tugas dan aktivitas yang menantang. Hasil penelitian ini sejalan dengan pendapat Callais (2009), bahwa diagram vee dapat memfasilitasi belajar dengan cara membantu siswa untuk mengorganisasikan dan mengintegrasikan informasi. Hindriana (2016) menyatakan apabila siswa mendapatkan pengetahuan secara komprehensif akan mengembangkan struktur kognitifnya, dengan struktur kognitif yang berkembang tidak saja meningkatkan pada ranah pengetahauan tetapi juga dapat meningkatkan pada ranah keterampilan dan sikap. Internalisasi pengetahuan dalam LKP yang dikembangkan menyajikan pengetahuan yang dikemas menjadi suatu informasi yang saling berhubungan dan memiliki makna, hal ini akan memudahkan siswa dalam mengelola informasi. Penyajian informasi tersebut sesuai dengan teori pemrosesan informasi bahwa informasi yang saling berhubungan akan menghilangkan keterbatasam working memory dalam memproses informasi (Schnotz \& Kürschner, 2007). (3) Berdasarkan hasil pengembangan LKP tersebut melalui aspek persepsi proses sains siswa sudah diarahkan untuk mampu melakukan penyelidikan melalui observasi, berpikir kritis dan memecahkan masalah melalui keterampilan interpretasi dan mengajukan hipotesis serta melaksanakan eksperimen melalui keterampilan merancang percobaan dan menggunakan alat bahan, sehingga aspek persepsi proses sains dapat mendukung terhadap penguasaan konsep secara bermakna. Hal ini sesuai dengan pendapat Marzano (1992), bahwa pembelajaran di kelas dapat dikatakan bermakna, apabila siswa sudah mampu mengambil keputusan, melakukan penyelidikan, melaksanakan eksperimen, memecahkan masalah, dan menemukan sesuatu. (4) Aspek transformasi diperlukan untuk memudahkan siswa dalam mengkomunikasikan data hasil praktikum, dan memudahkan untuk melihat pola data hasil praktikum. Dengan dilakukan transformasi terhadap data yang dikumpulkan akan mengembangkan keterampilan proses pada aspek interpretasi, prediksi dan mengajukan hipotesis. Karamustafaoğlu (2011) menyatakan bahwa dengan adanya transformasi data akan meningkatkan kemampuan siswa menghubungkan informasi-informasi yang didapat, dan memfasilitasi siswa untuk meningkatkan keterampilan proses sains terutama kemampuan mengajukan hipotesis.

\section{Kualitas Lembar Kerja Praktikum berbasis Diagram Vee}

Tahap uji coba merupakan tahap penilaian kualitas LKP dengan cara menyebarkan draf LKP yang dikembangkan yang dilengkapi rubrik (Novak dan Gowin, 2006) untuk menilai draf LKP kepada 12 orang guru yang akan menggunakan LKP hasil pengembangan. Berdasarkan hasil penilaian oleh guru didapat hasil sebagai berikut :

Tabel 2. Hasil Penilaian LKP Berbasis Diagram Vee

\begin{tabular}{clc}
\hline No & \multicolumn{1}{c}{ Aspek Penilaian } & $\begin{array}{c}\text { Rataan } \\
\text { nilai }\end{array}$ \\
\hline 1 & Tujuan & 3,9 \\
2 & Perisriwa/Objek & 3,7 \\
3 & Teori, Konsep dasar, & 3,8 \\
& dan Prinsip. & \\
4 & Transformasi data & 3,75 \\
5 & (Pencatatan) & 3,4 \\
6 & Perolehan Pengetahuan & 3,85 \\
\hline \multicolumn{2}{|l}{ Perolehan Nilai } & $\mathbf{3 , 7 3}$ \\
\hline
\end{tabular}

Berdasarkan hasil penilaian dari 20 orang guru, maka didapatkan hasil bahwa LKP yang dikembangkan mendapatkan penilaian dengan kriteria unggul $(3,73 / 4)$ setara dengan nilai 93,25 dan dapat diimplemetasikan di sekolah. Nilai terbesar pada aspek tujuan hal ini dikarenakan pada LKP yang dikembangkan tujuan mengarahkan siswa pada apa yang harus mereka amati, berbeda dengan LKP yang biasa dipakai disekolah dalam tujuan belum mengarahkan pada apa yang harus siswa amati. Hal-hal baru pada LKP yang dikembangkan mendapatkan nilai yang tinggi, diantaranya aspek tujuan yang berbeda dengan LKP yang 
biasa digunakan, aspek teori yang memiliki pola penyajian yang berbeda dengan LKP yang biasa digunakan, dan aspek perolehan nilai (valuasi) yang biasanya tidak ada di LKP yang biasa digunakan di sekolah.

\section{Respon Guru Terhadap LKP Berbasis Diagram Vee dalam Memfasilitasi Kegiatan Praktikum}

Respon guru terhadap LKP berbasis diagram vee dalam memfasilitasi kegiatan praktikum sebesar 3,44 hal ini menunjukkanbahwa LKP yang dikembangkan dapat diterima dan diimplementasikan pada siswa agar kegiatan praktikum menjadi bermakna.

Adapun rincian respon guru pada setiap aspek adalah sebagai berikut

Tabel 3. Hasil Respon Guru Terhadap LKP Berbasis Diagram Vee

\begin{tabular}{clc}
\hline No & \multicolumn{1}{c}{ Indikator } & $\begin{array}{c}\text { Rataan } \\
\text { Nilai }\end{array}$ \\
\hline 1. & $\begin{array}{l}\text { Ketepatan Teori } \\
\text { 2. }\end{array}$ & 3,65 \\
2.terkaitan Teori dengan & praktikum yang akan \\
dilaksanakan & 3,55 \\
3. & Kemudahan cara kerja & \\
praktikum & 3,65 \\
4. & Terdapat Hakikat Sains & 3,35 \\
5. & Ketepatan klaim & 3,00 \\
6. & Kengetahuan & 3,45 \\
7. & Kebermatan klaim nilai & 3,45 \\
\hline \multicolumn{2}{l}{ Rata-rata Praktikum } & $\mathbf{3 , 4 4}$ \\
\hline
\end{tabular}

Berdasarkan tabel 3. Aspek tertinggi yang mendapatkan penilaian tertinggi adalah pada aspek ketepatan teori, dan kemudahan cara kerja dalam praktikum. Kedua aspek yng mendapatkan penilian tertinggi disebabkan krena adanya perbedaan pola dalam penyajian informasi dibandingkan dengan LKP yang biasa digunakan di sekolah. Sedangkan aspek ketepatan klaim pengetahuan mendapatkan nilai terendah, hal ini dikarenakan biasanya klaim pengetahuan pada LKP yang biasanya dipakai disekolah tidak mengklarifikasi hasil praktikum tetapi lebih menekankan pada pertanyaan-pertanyaan yang bersifat menguji pengetahuan tentang konsep yang dipraktikumkan.

\section{SIMPULAN}

Berdasarkan hasil penelitian tentang pengembangan Lembar Kerja Praktikum Berbasis Diagram Vee, dapat disimpulkan bahwa LKP yang dikembangkan memiliki lima aspek yaitu valuasi biologi, internalisasi biologi, persepsi proses sains, serta analisis dan transformasi dapat dijadikan alternatif pengembangan LKP untuk memfasilitasi kegiatan praktikum secara bermakna. Kebermaknaan praktikum terfasilitasi karena LKP menekankan pada penyajian teori yang koheren dengan pengamatan objek atau kejadian, bersifat kontekstual karena hasil praktikum dihubungkan dengan permasalahan dalam kehidupan sehari-hari siswa, dan mengembankan inkuiri dengan cara penyelidikan dan penemuan terhadap objek atau peristiwa yang diteliti.

Hasil penilaian terhadap kualitas LKP berbasis diagram vee yang dikembangkan memperoleh rata-rata nilai sebesar 3,73 dan termasuk kategori sangat baik, sehingga LKP berbasis diagram vee layak untuk diujicobakan. Hasil penilaian LKP berbasis diagram vee mendapatkan respon yang baik dari guru yang akan memimplementasikan LKP hasil pengembangan.

\section{REFERENSI}

Afamasaga-Fuata'i, K (2009). Secondary Preservice Teachers' Use of Vee Diagrams to Analyse Problems and Illustrate Multiple Solutions. MathematicsTeacher Education and Development. Vol. 10. (15-29).

Agoro.A.A, Akinsola.M.K, (2013) Effectiviness of Reflective Reciprocal Teaching on Pre-Service Teachers' Achievement and Science Process Skills in Integrated Science", International Journal of Education and Reseach, 1, 1-20.

Amiel, T., \& Reeves, T. C. (2008). "DesignBased Research and Educational Technology: Rethinking Technology and the Research Agenda". Educational Technology \& Society, 11 (4), 29-40.

Alvarez dan Risko. (2007). The Use of Vee Diagram With Third Graders as A 
Metacognitive Tool for Learning Science Concept. Departement of Teaching and Learning Teaching and Learning Presentations.

Callais, G.J. ( 2009). The Vee Diagram as a Problem Solving Strategy: Content Area Reading/Writing Implications. National Forum Teacher Education Journal . Vol 19,(3), 1-8.

Farsakoğlu.O.F, Sahin.C, Karsli.F, (2012), “ Comparing Science Process Skill of Prospective Science Teacher : A Cross Sectional Study", Science Learning and Teaching, 13, (6), 1-21.

Gencer,A.S, (2014), "Analysing Vee Diagram Reflections to Explore Pre-service Science Teachers' Understanding the Nature of Science in Biology", Eurasia Journal of Mathematics, Science \& Technology Education, 10(5), 437-446

Hindriana, A.F., (2016), "The Development of Biology Practicum Learning Based on Vee Diagram for Reducing Student Cognitive Load". Journal of Education Teaching and Learning. 1,(1) 61-64.

Karamustafaoğlu.S., (2011), "Improving the Science Process Skills Ability of Science Student Teachers Using I Diagrams". Eurasian Journal of Physic and Chemistry. Education. 3(1):26-38

Marzano,R.J, (1992), A Different Kind of Classroom, Teaching with Dimension of Learning, Alexandria, Association for Supervision and Curriculum Development.

Novak, J. D \& Gowin D. 2006. Learning How To Learn. Cambridge, MA: Cambridge University Press.
Ormrod.J.E., (2008), Psikologi Pendidikan, Jakarta : Erlangga.

Schnotz.W., Kürschner.C., (2007), “A Reconsideration of Cognitive Load Theory". Educ Psychol.19, 469-508.

Safdar, Hussain, Shah, Tasnim., (2013) Make The Laboratory Work Meaningful Through Concept Maps and Vee. IOSR Journal of Research of Method In Education. Vol. 3 Issue 2 ( pp 55 -60 ) 2013 